\title{
A DOCÊNCIA NO CONTEXTO DO CURSO DE FORMAÇÃO DE PROFESSORES INDÍGENAS NO AMAZONAS: RELATOS DE APRENDIZAGENS
}

Fabiana de Freitas Pinto Universidade Estadual de Campinas

fabianapdg@hotmail.com

Ana Lúcia Guedes Pinto Universidade Estadual de Campinas alguedes@mpc.com.br

\begin{abstract}
RESUMO
$\mathrm{O}$ presente artigo, derivado do projeto de doutorado intitulado "O exercício da docência na perspectiva intercultural do Curso de Licenciatura Formação de Professores Indígenas da Universidade do Amazonas", objetiva discorrer sobre a dinâmica de trabalho de um grupo de professores que se lança ao desafio de ensinar nas continentais distâncias amazônicas e o que se tem aprendido nessa relação acadêmica com os povos tradicionais. Os relatos desse estudo foram captados pelo recurso da entrevista, transcritos e analisados à luz da perspectiva teóricometodológica da Historia Oral, o que nos ajudará na compreensão do rico e complexo processo formativo no qual os professores estão inseridos e a ampliação do olhar para uma prática docente ainda pouco reconhecida.
\end{abstract}

Palavras-chave: Formação de professores indígenas. História Oral. Aprendizagem na diversidade.

\section{THE TEACHING PROFESSION IN THE CONTEXT OF THE UNDERGRADUATE COURSE FOR INDIGENOUS TEACHERS AT THE AMAZON: LEARNING STORIES}

\begin{abstract}
This article, derived from the $\mathrm{Ph}$. D. project entitled "The exercise of teaching in the inter cultural perspective of the Undergraduate Course for Indigenous Teachers of the University of Amazonas", aims to expose the work dynamics of a group of professors that faces the challenge of teaching confronting the continental Amazonian distances, and what has been learned in this academic relationship with traditional peoples. The stories of this study were obtained through interviews, transcribed and analyzed in the light of the theoretical-methodological perspective of Oral History, which will help us to understand the rich and complex training process in which teachers are inserted, and to broaden the view towards a teaching practice still underrecognized.
\end{abstract}

Keywords: Training of indigenous teachers. Oral History. Learning in diversity.

\section{LA DOCENCIA EN EL CONTEXTO DEL CURSO DE FORMACIÓN DE PROFESORES INDÍGENAS EN EL AMAZONAS: RELATOS DE APRENDIZAJES}

\section{RESUMEN}

El presente artículo, derivado del proyecto de doctorado intitulado "El ejercicio de la docencia en la perspectiva intercultural del Curso de Licenciatura Formación de Profesores Indígenas de la Universidad del Amazonas", tiene por objetivo exponer la dinámica de trabajo de un grupo 
de profesores que se lanza al desafío de enseñar en medio de las continentales distancias amazónicas, y sobre lo que se ha aprendido en esta relación académica con los pueblos tradicionales. Los relatos de este estudio fueron obtenidos mediante entrevistas, transcriptas y analizadas a la luz de la perspectiva teórico metodológica de la Historia Oral, lo que nos ayudará a comprender el rico y complejo proceso formativo en el que los profesores se insertan, y a ampliar la mirada hacia una práctica docente todavía poco reconocida.

Palabras clave: Formación de profesores indígenas. Historia Oral. Aprendizaje en la diversidad.

\section{L'ENSEIGNEMENT DANS LE CADRE DE LA FORMATION DES ENSEIGNANTS AUTOCHTONES EN AMAZONIE: RAPPORTS D’APPRENTISSAGE}

\section{RÉSUMÉ}

Cet article, issu du projet de doctorat intitulé "L'exercice de l'enseignement dans la perspective interculturelle du cours de formation des enseignants autochtones de l'Université d'Amazonas", vise à discuter de la dynamique du travail d'un groupe d'enseignants qui lance le défi d`enseigner sur les distances continentales de l'Amazonie et ce qui a été appris dans cette relation académique avec les peuples traditionnels. Les rapports de cette étude ont été obtenus par des interviews, transcrits et analysés pour mieux comprendre la perspective théorique méthodologique de l'Histoire Orale, ce qui nous aidera à comprendre le processus formatif riche et complexe, encore peu reconnu, dans lequel les enseignants sont intégrés enseignant.

Mots clés: Formation des enseignants autochtones. Histoire Orale. l'Apprentissage dans la diversité.

\section{INTRODUÇÃO}

O presente artigo, resultado de parte dos estudos desenvolvidos na tese intitulada " $O$ exercício da docência na perspectiva intercultural do Curso de Licenciatura Formação de Professores Indígenas da Universidade Federal do Amazonas"”, objetiva discorrer sobre a dinâmica de trabalho de um grupo de professores que se lança ao desafio de ensinar nas continentais distâncias amazônicas e o que se tem aprendido com os povos tradicionais ${ }^{2}$ nessa específica relação acadêmica que se apresenta cotidianamente. Tais professores fazem parte do quadro docente efetivo do referido Curso e atuam em diversas áreas do conhecimento como Biologia, Letras, Matemática, Pedagogia, Geografia, Antropologia dentre outras, em um regime de colaboração entre professores de outros departamentos.

O Curso de Licenciatura Formação de Professores é relativamente novo e conta com um número ainda reduzido de docentes, necessitando assim de apoio de outros docentes da própria

\footnotetext{
${ }^{1}$ Ao longo do texto faremos uso da sigla FPI e UFAM para nos reportarmos ao Curso Formação de Professores Indígenas e à Universidade Federal do Amazonas, respectivamente.

${ }^{2}$ Referimo-nos às populações Indígenas.
} 
Universidade Federal do Amazonas e universidades colaboradoras, sensíveis ao trabalho com a diversidade para que as ações de ensino sejam integralmente realizadas.

É válido salientar que o Curso FPI nasceu da reivindicação do povo Mura, do município de Autazes, estado do Amazonas, indígenas que cursaram a formação do Magistério e ansiavam pela continuidade de seus estudos em nível superior. Inicialmente, intensos fóruns e seminários foram realizados pelos professores engajados na causa, em conjunto com a comunidade e suas lideranças ao longo dos anos de 2006 e 2007, até que se tornasse concreta sua implantação na universidade no ano de 2008. Hoje, vinculado à Faculdade de Educação (FACED) da UFAM, com características diferenciadas e um desenho curricular específico, o Curso almejando o atendimento das necessidades educacionais desse grupo, especialmente, definiu como seu principal objetivo:

Formar, em nível superior, numa perspectiva intercultural e interdisciplinar, professores indígenas para atuar na $2^{\mathrm{a}}$ etapa do ensino fundamental e no ensino médio, nas escolas indígenas, com habilitação plena nas áreas de Ciências Humanas e Sociais; Exatas e Biológicas; Letras e Artes. (UNIVERSIDADE FEDERAL DO AMAZONAS, 2007, p. 13).

Embora tenha iniciado e projetado suas atividades especificamente para turma Mura, que concluiu sua formação no ano de 2013, o objetivo acima mencionado continuou atendendo aos anseios pedagógicos das turmas que a sucederam assim como outras muitas ações esboçadas em seu Projeto Político-Pedagógico (PPP). Atualmente, tal documento passa por uma fase de reformulação buscando transformar-se e adaptar-se às especificidades dos graduandos atendidos pela Licenciatura.

A crescente demanda por ensino, inclusive, coopera substancialmente para a mudança mencionada no PPP do Curso. As especificidades culturais de cada turma a reivindicar o Ensino Superior são diversas e complexas, muitas vezes exigindo do Curso tanto adequações curriculares quanto estruturais. Povos indígenas de várias partes do Estado do Amazonas têm recorrido à UFAM com o intuito fazer parte do processo de formação disponibilizado pelo Curso FPI e, isso tem desafiado continuamente o fazer docente dos professores.

A logística a ser cumprida na realização de todos os módulos nos municípios, por exemplo, a nosso ver, é também um fator que merece ser destacado tendo em vista que as ações planejadas só conseguem ser concretizadas em sintonia com essa administração. O mapeamento abaixo contendo as informações sobre o funcionamento desse sistema foi elaborado com a intenção de melhor demonstrar o quantitativo que hoje compõe o Curso (turmas que se iniciam com 60 alunos) bem como os deslocamentos realizados pelos docentes envolvidos na dinâmica da formação em territórios amazônicos. Vejamos: 
Quadro informativo do Sistema Logístico do Curso Formação de Professores Indígenas:

\begin{tabular}{|c|c|c|c|}
\hline $\begin{array}{c}\text { Turmas atendidas pelo } \\
\text { Curso FPI }\end{array}$ & $\begin{array}{l}\text { Localidades de } \\
\text { realização da } \\
\text { formação }\end{array}$ & $\begin{array}{l}\text { Meios de transportes } \\
\text { utilizados no } \\
\text { deslocamento }\end{array}$ & $\begin{array}{l}\text { Tempo percorrido pelos } \\
\text { professores até os locais de } \\
\text { realização dos módulos do } \\
\text { Curso }\end{array}$ \\
\hline \multirow{2}{*}{$\begin{array}{l}\text { (1)Munduruku (indígenas } \\
\text { do Amazonas e Pará) - } \\
\text { aguardando processo de } \\
\text { formatura }\end{array}$} & Borba & $\begin{array}{c}\text { Manaus-Borba: } \\
\text { expresso }^{3}\end{array}$ & $\begin{array}{l}6 \text { horas (de acordo com o } \\
\text { movimento dos rios) }\end{array}$ \\
\hline & Manaus & $\begin{array}{l}\text { Manaus - Centro de } \\
\text { Formação: carro }\end{array}$ & $\begin{array}{l}45 \text { minutos - } 1 \text { hora (de acordo } \\
\text { com o trânsito) }\end{array}$ \\
\hline \multirow{3}{*}{$\begin{array}{l}\text { (2)Sateré-Mawé (indígenas } \\
\text { de Maués, Barreirinha e } \\
\text { Parintins) - aguardando } \\
\text { processo de formatura }\end{array}$} & \multirow[t]{2}{*}{ Maués } & Manaus-Maués: barco & $\begin{array}{l}16 \text { horas (de acordo com } \\
\text { o movimento dos rios) }\end{array}$ \\
\hline & & $\begin{array}{l}\text { Manaus-Maués: } \\
\text { táxi-aéreo }\end{array}$ & $45-50$ minutos \\
\hline & Manaus & $\begin{array}{l}\text { Manaus-Centro de } \\
\text { Formação: carro }\end{array}$ & $\begin{array}{c}45 \text { minutos - } 1 \text { hora (de acordo } \\
\text { com o trânsito) }\end{array}$ \\
\hline $\begin{array}{l}\text { (3)Médio Solimões (Mura, } \\
\text { Miranha, Kanamary, } \\
\text { Kambeba, Kokama, Apurinã } \\
\text { e Tikuna) - em processo de } \\
\text { formação }\end{array}$ & Manaus & $\begin{array}{l}\text { Manaus-Centro de } \\
\text { Formação: carro }\end{array}$ & $\begin{array}{c}45 \text { minutos - } 1 \text { hora (de acordo } \\
\text { com o trânsito) }\end{array}$ \\
\hline \multirow{2}{*}{$\begin{array}{l}\text { (4)Alto Rio Negro (Baniwa, } \\
\text { Tukano, Tariano, Tuiuka, } \\
\text { Kubeo, Baré, Carapanã, } \\
\text { Yepamansa e Arapasso) - em } \\
\text { processo de formação }\end{array}$} & \multirow[t]{2}{*}{$\begin{array}{l}\text { São Gabriel } \\
\text { da Cachoeira }\end{array}$} & $\begin{array}{r}\text { Manaus-São Gabriel } \\
\text { da Cachoeira: expresso }\end{array}$ & $24-26$ horas \\
\hline & & $\begin{array}{l}\text { Manaus-São Gabriel } \\
\text { da Cachoeira:avião }\end{array}$ & 2 horas \\
\hline \multirow{2}{*}{$\begin{array}{l}\text { (5)Alto Solimões (Tikuna e } \\
\text { Kambeba) - em processo de } \\
\text { formação }\end{array}$} & \multirow{2}{*}{$\begin{array}{l}\text { Benjamin } \\
\text { Constant }\end{array}$} & Manaus-Tabatinga: aviãd & 1 hora e 50 minutos \\
\hline & & $\begin{array}{l}\text { Tabatinga-Benjamin } \\
\text { Constant:voadeira }\end{array}$ & $20-30$ minutos \\
\hline \multirow[t]{2}{*}{$\begin{array}{l}\text { (6) Purus (Paumary, Apurinã, } \\
\text { Jarawara e Banawa) }\end{array}$} & \multirow[t]{2}{*}{ Lábrea } & $\begin{array}{l}\text { Manaus-Lábrea: } \\
\text { ônibus }\end{array}$ & $\begin{array}{l}16 \text { horas (nos períodos } \\
\text { de verão da região) }\end{array}$ \\
\hline & & $\begin{array}{l}\text { Manaus-Lábrea: } \\
\text { avião }\end{array}$ & 1 hora e 40 minutos \\
\hline $\begin{array}{l}\text { (7)Madeira (Mura, } \\
\text { Munduruku, Torá e } \\
\text { Parintintin) }\end{array}$ & Manicoré & $\begin{array}{l}\text { Manaus-Manicoré: } \\
\text { expresso }\end{array}$ & $\begin{array}{c}6 \text { horas e } 30 \text { minutos } \\
\text { (de acordo com } \\
\text { o movimento dos rios - subida } \\
\text { ou descida) }\end{array}$ \\
\hline
\end{tabular}

Fonte: http://www.aam.org.br ${ }^{5}$

\footnotetext{
${ }^{3}$ Embarcação estilo de lancha, comumente utilizada na região amazônica para transportar pessoas de um município ao outro e que possui maior velocidade/rapidez no deslocamento pela potência de seu motor.

${ }^{4}$ Embarcação de pequeno porte e com motor de popa utilizado constantemente para transportar passageiros aos municípios mais próximos de Manaus/AM.

${ }^{5}$ Além dessa fonte eletrônica foram consultados dados do arquivo pessoal da autora, anotados após a realização de viagens para alguns dos municípios citados no referido quadro.
} 
Ao observar o quadro acima e os longos caminhos percorridos pelos professores do Curso em questão, é possível perceber o quanto o ensino superior, num contexto territorial diferenciado se torna expressivamente desafiante, exigindo mais do que conhecimentos a serem ensinados/problematizados junto aos estudantes, mas uma significativa disposição física e psicológica e um constante apoio institucional. Trata-se de um movimento contínuo executado pelo Curso e que se intensifica ainda mais quando os módulos são realizados fora da capital, Manaus, onde está localizado o seu departamento.

Nesse caminho, é possível imaginar como o ritmo de vida dos professores também se altera em função das atividades docentes que acontecem em lugares tão distantes e com distintas realidades culturais no percurso de ensinar.

A reflexão trazida por Pimenta (2008, p.10), estudiosa da área de Formação de Professores no Brasil, nesse sentido, nos ajuda a compreender o quão importante se torna o papel do professor, sobretudo, numa realidade que se apresenta tão desafiadora:

\begin{abstract}
Certamente o que os professores e professoras são muito mais do que aquilo que fazem. Ao fazerem o que fazem eles instituem práticas que condicionam outros modos de ser porque exemplificam outras maneiras de ser. Isso quer dizer que há uma imbricação entre o ser e fazer, isto é, a realidade ontológica do ser professor conjuga-se com a realidade da episteme do fazer profissional do docente em ação. Se assim for, o professor é e está sendo, à medida que assume seu trabalho como condição de poder mais, justamente na mesma medida e que ele se desvencilha de velhas formas de pensar os processos pedagógicos.
\end{abstract}

Frente ao contexto da docência que se desenvolve numa perspectiva diferenciada e que busca se reinventar a partir das relações construídas com uma minoria historicamente excluída nos questionamos: Além de ensinar/formar futuros professores, o quê esses sujeitos-docentes do Ensino Superior têm aprendido nesse encontro com o "outro"? Que diferenças são percebidas em si e na sua prática a partir do diálogo com essa diversidade, os povos indígenas?

Mais adiante, por meio da problematização dos trechos que destacam as vozes desses docentes, vozes capturadas pelo recurso da entrevista, transcritas e analisadas à luz da História Oral é que pretendemos esboçar algumas respostas.

\title{
O ENCONTRO COM OS SUJEITOS DA PESQUISA: CRITÉRIOS METODOLÓGICOS ADOTADOS NO PERCURSO
}

As entrevistas realizadas com os professores do Curso FPI durante os meses de julho, agosto e dezembro de 2017 revelaram-se momentos de fecunda aprendizagem sobre a docência exercida junto às turmas indígenas no decorrer da Licenciatura. Os momentos de escuta, 
fundamentais para as pesquisas que adotam a História Oral como método de estudo/análise, nos permitiu navegar com intensidade nas narrativas dos doze professores ${ }^{6}$ participantes da investigação (tese), de modo que nos aproximássemos da compreensão de seus processos de constituição docente e de como vão ressignificando sua prática no cotidiano com sujeitos de costumes, culturas e linguagens tão peculiares. Os depoimentos, eivados de auto-reflexões, críticas e aprendizados mostraram-nos algumas importantes respostas às indagações feitas na introdução desse artigo e que, no nosso entendimento, constrói o cerne do diálogo que aqui estamos propondo.

Antes de voltarmos nossos olhares para os trechos dos depoimentos dos participantes da pesquisa, faz-se necessário esclarecer que a escolha pela perspectiva da História Oral se deu nesse trabalho por entendermos, assim como Alberti (2013, p. 24), destacada historiadora brasileira, que:

[...] é um método de pesquisa (histórica, antropológica, sociológica etc.) que privilegia a realização de entrevistas com pessoas que participaram de, ou testemunharam, acontecimentos, conjunturas, visões de mundo, como forma de se aproximar do objeto de estudo. [...] Trata-se de estudar acontecimentos históricos, instituições, grupos sociais, categorias profissionais, movimentos, conjunturas etc. à luz de depoimentos de pessoas que deles participaram ou os testemunharam.

Tal metodologia, que se ancora na fonte oral como forma de privilegiar o ponto de vista dos sujeitos comuns que testemunharam os fatos históricos perseguidos pela pesquisa, nos ajudou a percorrer o universo docente através das narrativas dos professores efetivos e colaboradores do Curso FPI.

Conforme rememoravam nas entrevistas suas experiências de ensino junto aos povos indígenas, permitiam-nos perceber que além de ensinar também aprendiam (aos moldes de Paulo Freire), ou seja, não era possível apenas um mergulho "raso" nessas águas, mas com profundidade, de modo que saíssem transformados dessa dinâmica academicamente e culturalmente diversa. Os encontros presenciais dedicados às entrevistas foram relativamente breves, com uma duração média de uma hora e uma hora e meia, mas muito intensos. Os professores se mostraram solícitos no processo de investigação e empenhados na elaboração de

\footnotetext{
${ }^{6} \mathrm{O}$ critério utilizado para a escolha dos professores participantes da pesquisa se deu pela efetividade no Curso e o tempo de atuação no mesmo. Nesse caso, doze (12) se encaixaram nos requisitos sendo nove (9) docentes do quadro permanente do Departamento de Educação Escolar Indígena e três (3) docentes de outros departamentos que atuaram em regime de parceria desde a criação do Curso. Cabe destacarmos que, coincidentemente, desse total de participantes: 6 são professores e 6 são professoras. Um (1) deles indígena da etnia Baniwa (região de São Gabriel da Cachoeira) e o restante não-indígena. Embora a pesquisa não tenha captado dados relativos à idade dos entrevistados, mas o tempo de suas atuações no Curso, foi possível perceber as diferenças entre as gerações.
} 
seus depoimentos. Durante as situações de entrevista, conseguimos criar um ambiente agradável e dinâmico na tentativa de afastar a tensão que envolve a presença do objeto gravador. Foi perceptível no início de alguns relatos certa intimidação/inibição, pelo fato de suas vozes estarem sendo gravadas, mas ao longo do processo esse sentimento ia se dissipando e permitindo que a sensação de conforto fosse tomando conta do entrevistado e de nossa também. Não é uma tarefa muito simples conduzir uma entrevista. Na verdade, são muitas as responsabilidades a serem desempenhadas pelo entrevistador a fim de que sejam alcançados os objetivos propostos na investigação e é imprescindível seguir os princípios da metodologia adotada.

Assim, atentos aos cuidados que devem existir no momento-chave da pesquisa demonos conta e reconhecemos o quão importante é o que nos colocam Santhiago e Magalhães (2015, p. 114) a respeito da entrevista:

[...], o ato de entrevistar não consiste apenas em ligar o gravador e fazer qualquer pergunta a qualquer pessoa. Além da preparação necessária, cuidados na hora da gravação são mais que recomendáveis, imprescindíveis. A esse título, poderíamos ressaltar os itens indispensáveis para o sucesso de um encontro: a forma correta de se fazer perguntas, uma linguagem adaptada ao entrevistado, a polidez no trato com o interlocutor e um bom manuseio do equipamento.

Tendo em vista todos esses critérios essenciais para uma entrevista bem sucedida, acreditamos ter cumprido requisitos importantes quando do contato prévio com os professores escolhidos, explicando-lhes os pormenores da pesquisa, da flexibilidade por nós demonstrada ante as datas por eles marcadas assim como os locais, o diálogo estabelecido sobre a presença do gravador no ato da entrevista, das possíveis inferências que podiam ocorrer de nossa parte com o intuito de construir uma relação de confiança e cumplicidade. Enfatizamos, de igual modo, o respaldo ético ${ }^{7}$ com que podiam contar no decorrer da pesquisa, apresentamos o Termo de Consentimento Livre e Esclarecido (TCLE) e todos os pontos que o compõem de modo a assegurar o sigilo de suas identidades e a liberdade de continuar ou não fazendo parte da pesquisa. Mediante tais esclarecimentos e com o consentimento de todos os participantes prosseguimos com as entrevistas, observando e extraindo das mesmas os depoimentos que foram nos ajudando a enxergar com mais nitidez esse rico palco de experiências, que brotam da vivência formativa com os graduandos indígenas.

${ }^{7} \mathrm{O}$ projeto de pesquisa citado no referido artigo foi submetido à apreciação do Comitê de Ética em Pesquisa (CEP/Unicamp) em 02 de maio de 2017 e recebeu aprovação no dia 28 de junho do mesmo ano através do Parecer n. 2143636. 
É válido ressaltar que, como se trata apenas de um recorte de um projeto maior, nem todos os relatos de aprendizagem dos doze professores puderam ser expostos no presente artigo, mas acreditamos que os escolhidos representarão significativamente as experiências docentes relatadas, de certo modo, por eles no tempo de atuação com os graduandos indígenas.

Os trechos apresentados a seguir surgem das narrativas construídas pelos professores quando indagados sobre a escolha pelo exercício da docência com povos indígenas, os limites e as possibilidades do trabalho docente com os professores indígenas e como que têm voltado o olhar para sua própria formação atuando como docente num contexto específico e diferenciado. Tais perguntas deram vazão a expressivas respostas, ao nos debruçarmos nesses relatos. A questão da diversidade, externalizada a partir dessa experiência, nos mostra que as distâncias culturais quando superadas, nos permitem aprender sempre e em qualquer circunstância. Para dar mais subsídios a essa nossa reflexão como educadores-aprendizes, destacamos o que Freire (2000, p. 40) nos diz:

\begin{abstract}
A educação tem sentido porque o mundo não é necessariamente isto ou aquilo, porque os seres humanos são tão projetos quanto podem ter projetos para o mundo. A educação tem sentido porque mulheres e homens aprenderam que é aprendendo que se fazem e se refazem como seres capazes de saber, de saber que sabem, de saber que ainda não sabem. De saber melhor o que já sabem, de saber o que ainda não sabem. A educação tem sentido porque, para serem, mulheres e homens precisam de estar sendo. Se mulheres e homens simplesmente fossem não haveria porque falar em educação.
\end{abstract}

\title{
RELATOS DOS PROFESSORES DO CURSO FPI SOBRE O APRENDER COM O ÍNDIO
}

As experiências docentes narradas pelos professores do Curso FPI são diversas, instigantes e descrevem os limites e as possibilidades de uma prática educativa voltada para a diversidade dos povos indígenas em territórios amazônicos. Ao nos aprofundarmos nos depoimentos dos professores, sujeitos da pesquisa, fomos nos deparando com suas impressões iniciais em torno do trabalho com grupos etnicamente diferenciados e aos poucos compreendendo os sentimentos envolvidos no encontro com um universo, que para alguns, era completamente desconhecido. Vejamos a narrativa abaixo:

"[...] o universo indígena sempre me atraiu por causa da diferença da cultura, por causa da diversidade que a gente encontra nesse meio, mas eu não tinha experiência prévia com isso e, na realidade, pouco conhecia desse universo. A gente, não sei se apenas eu, mas enfim, eu acho que a gente tem sempre uma ideia do universo indígena muito diferente do que ela é na realidade, acho realmente que só a experiência do universo indígena faz com que a gente compreenda verdadeiramente, realmente o que significa diversidade cultural... E é também e foi, no meu caso, na prática que eu fui aprendendo o 
significado dessa palavra "diversidade cultural" e fui buscando formas de trabalhar dentro desse universo cultural diverso do nosso" $\left(P 1^{8}\right)$.

Destaca-se na fala de P1, o desejo de conhecer o diferente, manifestado por seu dizer "o universo indígena sempre me atraiu" e, ao mesmo tempo, evidencia-se o quanto o aprendizado sobre a diversidade cultural se realiza nesse novo e específico contexto a partir "verdadeiramente", como afirma P1, da convivência cotidiana e prática.

Nos depoimentos, dá-se visibilidade de que, aos poucos os professores formadores vão aprendendo a lidar com o impacto que as diferenças culturais a priori costumam causar e com a multiplicidade de funções assumidas na profissão:

“[...] ser professor do Curso Formação de Formação de Professores Indígenas não é, não significa só trabalhar em sala de aula com os alunos, significa também um comprometimento que a gente acaba tendo com a causa indígena, comprometimento também que a gente acaba tendo com os nossos alunos diante das necessidades que eles nos apresentam. Então, eu acho que é muito gratificante trabalhar com eles, pelo retorno que a gentetem no sentido de que a gente colabora pra que eles alcancem esse ideal de uma escola indígena que realmente atenda aos interesses deles, isso é muito gratificante" $(P 1)$.

A exemplo do que é ser professor na dinâmica do Curso de Formação de Professores Indígenas, os docentes também indicam em seus dizeres que vão aprendendo que planejar e ministrar o conteúdo em suas disciplinas já não constam mais como atividades únicas no seu cotidiano. É preciso aprender a assistir os alunos de outras maneiras e se articular para que algumas necessidades, teoricamente a serem atendidas por outras instâncias da universidade, não inviabilizem a estada dos graduandos nos locais de formação, por exemplo, e nem prejudiquem o andamento das atividades acadêmicas que acontecem por módulos/etapas. Vejamos o seguinte depoimento:

"[...] me aproximo do Curso Formação de Professores Indígenas com... é... com certo receio do que eu iria encontrar aqui, porque até então eu sabia... eu conhecia a especificidade, mas não vivia essa especificidade... do Curso Formação de Professores Indígenas... E foi nesse viver a especificidade que aí, eu entrei em choque com muitas questões... porque uma coisa é você pensar o que é específico, uma coisa é você viver o que é específico e esse viver foi pra mim um furacão no início. [...], às vezes, a gente fala pras pessoas, mas parece que as pessoas não compreendem, parece que a gente está fazendo uma narrativa de algo que é de outro mundo, não sei, mas só vai compreender especificamente o quê que é o FPI quem vive o FPI. Todas as suas dinâmicas de interação com os alunos, com a logística, com o financeiro... você tem que fazer um turbilhão de coisas que, naquele momento é... eu achava que não era

\footnotetext{
${ }^{8}$ Essa sigla fará referência aos professores, autores dos trechos escolhidos para compor o artigo, e seguirão sequenciados dessa maneira: P1, P2, P3..., obedecendo assim, o sigilo das identidades. As entrevistas foram realizadas em grande parte na Universidade Federal do Amazonas, localizada na cidade de Manaus, ao longo dos meses de julho, agosto e dezembro de 2017, conforme a disponibilidade e sugestão dos participantes.
}

Rev. Iberoam. Patrim. Histórico-Educativo, Campinas (SP), v. 4, n. 2, p. 396-411, jul./dez. 2018 
atividades do docente. Então, você, por exemplo, ter que... dormir na fazenda ou... apesar de que eu nunca dormi na fazenda ou ter que, por exemplo, acompanhar aluno em hospital, fazer compras... Uma das coisas que no início mais me deixava furioso, digamos assim, era ter que dar conta de uma estrutura pessoal do aluno [...] e a gente conta isso pras pessoas, as pessoas acham... "você faz isso?". É... enfim, é uma outra discussão, mas... no início isso pra mim foi um choque... foi um choque muito grande porque é tudo muito... tudo muito diferente do que a gente possa imaginar enquanto Curso de graduação. Então, a gente não chega aqui só pra dar aula "tenho aula de tanto a tanto, chego, comento o material, dou a minha aula e depois eu tenho tempo livre pra fazer outra coisa", não, você tem que se dedicar quase que 24 pro Curso, pra turma [...]" (P2).

Apesar dos contratempos mencionados como acompanhar os alunos em hospitais, fazer compras, isto é, "dar conta da uma estrutura pessoal do aluno"," encontrados nesse caminho da docência com os povos indígenas, os professores do Curso FPI parecem se dar conta de um amadurecimento ao longo das experiências, reconhecendoa importância das atividades voltadas a essa minoria que se dedica à continuidade de seus estudos para a consolidação da sua autonomia e de suas escolas e percebem ainda os reflexos positivosdessas ações na vida de seus alunos. Não se trata apenas de cumprir uma obrigação, mas imprimir um sentido às vivências construídas junto aos professores indígenas:

“[...] apesar de todo esse sacrifício, quando a gente está com eles, quando a gente conversa com eles, quando a gente os ouve e quando a gente enxerga eles, a gente percebe o quanto que eles valorizam essa formação no sentido de que isso não vai ser só um diploma a mais para eles ou um diploma pra eles, mas que isso também é algo que potencializa o viver da comunidade indígena e quanto que isso é importante [...] e eu enxergo essas potencialidades aí. [...], eu percebi o quanto que eu mudei daquele que entrou lá em 2013, com todas aquelas angústias e com todos aqueles parafusos, aquele furacão de se perguntar "será que eu estou no lugar certo?"[...], pro que ministrou Metodologia do Estudo e da Pesquisa pra turma Lábrea em dois mil e dezesseis. Eu fui perceber o quanto eu tinha amadurecido na compreensão do Curso com todas as suas dificuldades e com todo o seu esforço e com todo o esforço físico também que a gente faz, eu fui começando a compreender a importância do Curso para os povos indígenas, compreendendo muito mais do que eu já compreendia antes e compreendo a importância de nós, professores do FPI, estarmos juntos nessa briga com os povos indígenas, nessa briga por manter, por levar adiante esse Curso" (P2).

A relação de proximidade dos docentes ao longo do tempo com os graduandos indígenas, a disponibilidade de ajudá-los nesse processo que exige muito esforço e até mesmo renúncias, e a vontade de transpor as barreiras surgidas no cotidiano acadêmico em que as

\footnotetext{
${ }^{9}$ Referimo-nos aos momentos em que as turmas se deslocam de suas comunidades/municípios para o Centro de Formação de Professores, localizado na Fazenda Experimental da UFAM (BR 174), a 38 km de Manaus/AM, para a realização dos módulos/etapas de formação. Frente às condições de desconhecimento do lugar e distanciamentos dos pontos comerciais e outros estabelecimentos como bancos e hospitais, por exemplo, os alunos indígenas acabam tendo que recorrer aos professores para o suprimento de algumas de suas necessidades ao longo de sua estada no Curso, como as que foram citadas no corpo deste artigo.
} 
diferenças se fazem presentes aventam chances cada vez maiores de compreensão desse universo que se apresenta, muitas vezes tão complexo. Não é possível desvendá-lo em curto prazo e sem o trabalho calcado na perspectiva das possibilidades. A narrativa a seguir nos fornece algumas demonstrações:

\begin{abstract}
"E com esse passar de tempo também vejo que eu passei a compreendê-los melhor, coisa que quando a gente é verdinho, né, que a gente entra aqui e vai trabalhar com os Sateré, com Munduruku que não falam a língua, até com os Mura de Autazes ${ }^{10}$ que sofreram tanto, perderam tanto da sua cultura devido o contato... Mas, quando a gente lida com eles... nossa, vai aprendendo tantas coisas. [...], a formação, eu digo que ela, pro contexto do Curso, é uma caminhada que tem sido lenta, mas até que enfim, já estou vendo engatinhar pra caminhar, como diz o Yanomami, ela ocorre aqui dentro, é uma formação continuada que vem no dia a dia, entendeu? Com os desafios, com os alunos, com as turmas, com as idas e vindas na aldeia, com a administração do Curso, porque a academia não nos prepara pra nada disso aqui..." (P3).
\end{abstract}

Os desafios que se apresentam na realidade do Curso FPI como bem são destacados no depoimento do professor (P3) se tornam cada vez mais expressivos e vão indicando os muitos entraves enfrentados por aquelesque se lançam ao apoio da causa indígena por meio da Educação. Ao que nos parece não são muitas as alternativas que possam minimizar esse enfrentamento, em contrapartida, encará-los tem tornado o corpo docente cada vez mais fortalecido e preparado para lidar com as diversas questões burocráticas impostas pela academia e com a própria sensação de insegurança quando à frente de um mundo ainda pouco conhecido. Nesse caminho também dão pistas de como tem sido aprender com os conhecimentos e experiências que ultrapassam os limites da sala de aula. $\mathrm{O}$ extenso relato nos mostra a riqueza de um novo aprendizado e como isso acaba se tornando um diferencial na trajetória docente daqueles que se permitem vivenciar a cultura do outro:

\begin{abstract}
"Quando a gente começa a trabalhar os conteúdos, as disciplinas eu vejo a troca de conhecimentos entre culturas, né? E isso, eu estou falando de turmas com povos únicos... Quando a gente vai pensar turma Médio Solimões é uma turma que tem 8 povos... Nossa! Eu vejo [...] um fervilhão de interculturalidade [...] isso eu vi muito com nossos alunos, a troca assim, de conhecimentos do cotidiano, do dia a dia... Eu já tive várias vezes junto com os meninos e doente, uma coisa recente que eu passei na minha vida, recente mesmo... Eu nunca quis esse negócio da benza... benzedeira e nada disso. Eu tava na aldeia e tive uma distensão muscular, tava sentindo muita dor e aí, o indígena Sateré que tava com a gente falou: "olha, eu vou lhe levar com minha mãe. O senhor não quer ir lá?"'Eu falei: "é..., isso não funciona”. Mas, por educação eu fui, né... E aí, é uma ciência que eu nunca cri, entendeu? Falei: "isso não vai funciona, isso é psicológico" e dei as costas pra ela fazer o procedimento e aí, vou te falar, o negócio resolveu! Na hora que ela ia fazendo, era dando uns nós lá sem tocar em mim, eu sentia uma coisa passar,
\end{abstract}

${ }^{10}$ Sateré-Mawé, Munduruku e Mura - etnias as quais pertencem os indígenas do curso de formação. As populações indígenas que fazem parte dessas etnias estão situadas em diferentes regiões do estado do Amazonas e Pará (no caso dos Munduruku) e possuem culturas, costumes e línguas diferentes uma das outras.

Rev. Iberoam. Patrim. Histórico-Educativo, Campinas (SP), v. 4, n. 2, p. 396-411, jul./dez. 2018 
entendeu, parecia que... E aí, sentia a pele esquentar, logo após deu um cansaço enorme, deu um sono enorme parecia que eu tinha saído de uma pequena cirurgia onde eu tinha sido sedado. Me passou umas recomendações: "faça isso, isso e isso durante 3 dias pra poder ter resultado". E assim fiz e olha, funcionou! Coisa que quando isso acontece não resolve fácil na nossa ciência, com nossos remédios... E então, eu te pergunto: eu, não crente naquilo, que vivi aquilo... Tu acha que eu vou agora... está entendendo... a troca? Eu me dispus também a viver a experiência e isso só me aconteceu porque eu estava em aldeia, entendeu, trabalhando no meu contexto do Curso, está entendendo? Então, isso é interculturalidade, isso é diferencial que se..., como fui falar pro meu colega [...] ele vai começar a rir da minha cara, aí eu vou falar: "poxa, mas funcionou pra mim!'Mas, pra ele vai continuar naquela visão que se o índio quiser fazer o nosso, do PIBIC ${ }^{11}$ deles sobre o benzimento, a reza pra curar... Nossa! Isso é um absurdo e não vai ser ciência. Mas, ele vai na acupuntura, ele vai não sei o quê, vai no outro oriental que está do outro lado do mundo que acaba sendo quase a mesma coisa, entendeu? E aí, a visão dele de interculturalidade ta mais parca que a minha já nesse contexto, porque eu vivi isso, me dei a viver isso, entendo, compreendo porque estive lá. Então, poxa, sou mais intercultural que ele, entende?" (P3).

A narrativa acima nos apresenta aspectos importantes da cultura do outro, do diferente e como os conhecimentos tradicionais vão buscando dialogar no processo formativo empreendido pelos professores do curso.

Silva (2000), antropólogo estudioso da cultura afro-brasileira, principalmente, do candomblé, problematiza os desafios vividos pelos pesquisadores quando se inserem no campo alheio. O autor chama atenção para as muitas outras dimensões que são abertas/vivenciadas quando a interlocução passa a ser cada vez mais profunda com o outro. P3, quando relata que se permitiu participar de um dos mais sagrados processos ritualísticos de uma comunidade indígena - o benzimento/a reza - o professor, apesar de expressar todo um estranhamento e uma resistência inicial, vai também dando a ver em sua fala uma ampliação do seu olhar para o mundo outro, desconstruindo determinados "pré-conceitos" a respeito daquilo que até então não havia sido vivenciado por ele e, principalmente, aprendendo com a bagagem cultural trazida pelos povos indígenas, seus alunos e indivíduos com cosmológicas próprias, costumes praticados milenarmentee significativos saberes empíricos.

O depoimento, além de nos proporcionar a riqueza e a eficácia de um ritual experimentado por um não-indígena, nos apresenta uma perspectiva indispensável no trabalho acadêmico e nas demais relações empreendidas com os grupos culturalmente diferenciados, que é a interculturalidade. Mas, o que é interculturalidade? Como ela acontece? Santiago, Akkari e Marques (2013, p. 21-22) esclarecem que:

A perspectiva intercultural se configura em uma proposta de "educação para a alteridade" aos direitos do outro, à igualdade de oportunidades, uma proposta

\footnotetext{
${ }^{11}$ Programa Institucional de Bolsas de Iniciação Científica (PIBIC).
} 
democrática mais ampla que, no mundo anglo-saxão, define-se como educação multicultural e que, nos países europeus, assume diferentes denominações: pedagogia do acolhimento, educação para a diversidade, educação comunitária, educação para a igualdade de oportunidade ou, simplesmente, educação intercultural.

A princípio o termo parece ser complexo, dada as suas muitas denominações e variações conceituais, mas, se compreendido, nos garante um aprendizado especial no campo da educação e uma convivência mais humana frente às diferenças que nos compõem enquanto sujeitos. Para tornar mais evidente a importância de se entender e viver a interculturalidade nos mais variados espaços sociais, especialmente, nos ambientes escolares e com os sujeitos de culturas diferentes é necessário a reflexão trazida também por Santiago, Akkari e Marques (2013, p. 24) onde colocam que:

\begin{abstract}
A adoção de uma perspectiva intercultural pode repercutir no cotidiano das instituições educacionais, favorecendo o diálogo entre as diferenças e problematizando discursos que essencializam as identidades. Os autores destacam a importância de se formar profissionais da educação interculturalmente orientados, conscientes da necessidade de promover um ensino culturalmente sensível que considere as perspectivas dos alunos provenientes de diversos grupos culturais e com identidades múltiplas de gênero, raça, padrões linguísticos.
\end{abstract}

Nessa perspectiva, que tem a diversidade como componente fundamental para as interações humanas e aprendizado entre os sujeitos das mais variadas origens, identidades e costumes observamos o quanto os professores têm se preocupado em construir práticas interculturais no contexto de suas profissões docentes. Não são poucos os depoimentos que discorrem sobre a interculturalidade como princípio adotado no cotidiano das ações formativas da Licenciatura. Embora o termo - intercultural - não esteja impresso na nomenclatura do Curso, eles demonstram em seus dizeres o quanto ela está presente no processo de formação dos professores indígenas, o quanto ela pode promover mudanças de consciências, conceitos e estruturas, sobretudo, na universidade e o quanto tem aprendido com isso:

“[...], a gente acredita numa interculturalidade que vá mexer com a estrutura da UFAM, que vai mexer com essas coisas da estrutura e dos poderes e das verdades e chegue nessa questão do diálogo de ciências. [...]. Acho que a interculturalidade que o curso coloca e, talvez, os professores de outras áreas poder falar isso mais, não é, é realmente você encarar que você está falando com diálogos de pensamentos. Então, isso também tem que desmontar toda aquela visão de que o índio pensa menos, que o índio, que é uma visão que tinha bem tradicional, que não é só de indio não, pessoal que recebe preconceitos sobre outras... [...] Então, a interculturalidade no Curso como uma possibilidade se você realmente mergulhar nisso, só que é um desafio que é difícil, não é, saí fumacinha, a gente fica querendo acertar e, às vezes, não é fácil acertar, então... Mas, acho que essa possibilidade de diálogo de saber outras saídas pro mundo, outras saídas pedagógicas que os índios estão criando" (P4). 
Nota-se que assumir o desafio da interculturalidade significa também assumir uma postura crítica frente ao mundo que, a nosso ver, ainda não está suficientemente aberto ao diálogo com a diversidade. Um caminho complexo, permeado de conflitos e resistências e que não pode ser pensado e construído só por uma parcela da sociedade como os professores, por exemplo, que já se vêem constantemente desafiados pelo compromisso de mudar o futuro do país, pelo contrário, que requer empenho e luta de todos os outros segmentos sociais que buscam uma convivência mais democrática em nosso meio. Mas, para que isso aconteça é inadiável conscientizarmo-nos, como colocam Gomes e Silva (2011, p. 20-21), de que:

\begin{abstract}
A diversidade como uma questão para a educação e para a sociedade não é mérito de pesquisadores/as iluminados/as, de currículos emergentes e nem de centros de formação com propostas inovadoras. Antes, ela é fruto da ação dos sujeitos no interior da sociedade e nos movimentos sociais. É resultado da luta desses mesmos sujeitos pela construção de espaços públicos e pelo tratamento democrático e igualitário às diferenças.
\end{abstract}

\title{
CONSIDERAÇÕES FINAIS
}

Desafiados a dialogar sobre a realidade docente do Curso de Formação de Professores Indígenas da Universidade Federal do Amazonas, que se debruça sobre a longa e sinuosa realidade amazônica, acreditamos ter conseguido apresentar os muitos desafios enfrentados por seus professores no trajeto de ensinar e, principalmente, o que eles têm aprendido nessa relação com alunos de culturas e costumes tão diferenciados.

Partindo da perspectiva metodológica da História Oral procuramos reconstituir algumas das experiências desses sujeitos e mostrando as particularidades das histórias docentes que os tem transformado enquanto pessoas comuns e profissionais. Acreditamos que, com os relatos dos docentes pudemos reafirmar aquilo que nos diz Thompson (1992, p. 44) a respeito das muitas contribuições dessa metodologia:

\footnotetext{
A História Oral é uma história construída em torno de pessoas. Ela lança a vida para dentro da própria história e isso alarga seu campo de ação. Admite heróis vindos não só dentre os líderes, mas dentre a maioria desconhecida do povo. Estimula a professores e alunos a se tornarem companheiros de trabalho. Leva a história para dentro da comunidade e extrai a história de dentro da comunidade. Ela ajuda os menos favorecidos, especialmente os idosos, a conquistarem dignidade e autoconfiança. Propicia o contato - e a compreensão - entre classes sociais e entre gerações.
}

Diante desse olhar sensível proporcionado por essa teoria metodológica procuramos enfatizar o profundo aprendizado vivido pelos professores que se dispõem ao trabalho com os 
povos indígenas. Como pudemos perceber nas narrativas que compuseram este artigo, é um trabalho que nasce das nuances da diversidade cultural que surgem no decorrer das atividades docentes, um trabalho que enfrenta muitas dificuldades nos territórios acadêmicos e fora deles, mas que persiste acreditando não só nas mudanças estruturais da universidade, mas na mudança das mentalidades das pessoas que ainda não se abriram para o diálogo com as diferenças.

Os professores em seus depoimentos nos fornecem ricos exemplos dos ganhos que se têm quando as barreiras impostas pelos preconceitos são ultrapassadas, o quanto o ato de ensinar ganha mais sentido quando também se permite aprender com o outro.

Temos ciência de que o caminho é longo até que essas ações docentes possam ser reconhecidas e apoiadas como merecem, seja nas próprias instituições em que são projetadas ou fora delas. Mas, nessa direção, é necessário prosseguir acreditando, construindo novos e possíveis caminhos para a docência, como assim demonstraram fazer os professores-sujeitos apresentados nesse artigo. Educadores que se lançaram ao desafio da interculturalidade, que se dispuseram ao trabalho de tornar real um projeto de formação específico e diferenciado para e com os povos indígenas, mesmo diante de tantas adversidades. Esperamos, finalmente, que o diálogo aqui iniciado possa se estender às outras experiências docentes existentes pelo país, que se dedicam à formação de professores na perspectiva da diversidade e que muitas outras barreiras impostas às minorias sejam superadas por meio da Educação.

\section{REFERÊNCIAS}

ALBERTI, Verena. Manual de História Oral. 3. ed. rev. atual. Rio de Janeiro: FGV, 2013.

FREIRE, PAULO. Primeira Carta: Do espírito deste livro. In: Pedagogia da Indignação: cartas pedagógicas e outros escritos. São Paulo: Editora UNESP, 2000.

GOMES, Nilma Lino; SILVA, Petronilha B. Gonçalves (Orgs.). O desafio da diversidade. In: - Experiências étnico-culturais para a formação de professores. 3. ed. Belo Horizonte: Autêntica, 2011. (Coleção Cultura Negra e Identidades).

PIMENTA, Selma Garrido. Apresentação. In: GHEDIN, Evandro; AMEIDA, Maria Isabel de; LEITE, Yoshie Ussami Ferrari. Formação de Professores: caminhos e descaminhos da prática. Brasília: Líber Livro, 2008.

SANTHIAGO, Ricardo; MAGALHÃES, Valéria Barbosa de. História Oral na sala de aula. Belo Horizonte: Autêntica, 2015. (Coleção Práticas Docentes).

SANTIAGO, Mylene Cristina; AKKARI, Abdeljalil; MARQUES, Luciana Pacheco. Os caminhos do interculturalismo no Brasil. In: Educação Intercultural: desafios e possibilidades. Petrópolis, RJ: Vozes, 2013. 
SILVA, Vagner Gonçalves da. O antropólogo e sua magia. São Paulo: Edusp, 2000.

THOMPSON, Paul. A Voz do Passado: História Oral. Rio de Janeiro: Paz e Terra, 1992.

UNIVERSIDADE FEDERAL DO AMAZONAS. Faculdade de Educação. Projeto Pedagógico e Regulamentação do Curso de Licenciatura Formação de Professores Indígenas. Manaus, 2007. 